\title{
REVIEW SERIES
}

\section{Chronic obstructive pulmonary disease -8 : Non-pharmacological management of COPD}

\section{D L Morgan, J R Britton}

Thorax 2003;58:453-457

The role of smoking cessation and the use of measures to reduce the disability associated with COPD are reviewed. The political profile of patients with COPD is increasing as patient support groups develop the confidence to campaign for better services.

n common with other chronic diseases, the image of chronic obstructive pulmonary disease (COPD) conveys a sense of despair and therapeutic futility in both the patient and the health professional. The condition is perceived as selfinflicted and irreversible and therefore public interest is low. For the present there is no realistic expectation of pharmacological reversal of impairment, so investment from the pharmaceutical industry is limited to exploring symptom reduction alone. Furthermore, since COPD is not associated with a routine surgical procedure or high identified treatment costs, there is correspondingly little political pressure to improve the provision of services. Until recently the true societal costs of COPD were unrecognised, but recent investigations have at last uncovered the true burden of the disease which may begin to concern government. ${ }^{1}$ In addition, patient organisations are beginning to understand that people with COPD are victims of their own susceptibility as well as the exploitation of the tobacco industry. They are therefore demanding a less judgmental and more equitable provision of service. Clinical research in COPD has been heavily biased towards pharmacological treatment. However, there is a growing body of evidence for the benefit of non-pharmacological treatment in the reduction of disability and handicap from the disease. This review will look beyond the inadequate opportunities for reversing airway obstruction and hopefully provide some therapeutic optimism for patients and therapists.

In recent years it has been recognised that the pathophysiology of COPD extends beyond the airways to include other body systems. The recognition that COPD is a systemic illness implies that treatment must be multidimensional. Unlike asthma, attention to the airway alone is unlikely to have a major therapeutic or health economic benefit without regard to secondary prevention, rehabilitation, early detection, and organisation of care. In COPD the only real current opportunity for disease modification lies in early detection and smoking cessation. In other areas there are opportunities for reducing disability and handicap through rehabilitation and improving the delivery of care. Most clinical guidelines on COPD still promote a stepwise approach to management. However, the generally late presentation of COPD should favour simultaneous consideration of all treatment modalities including nonpharmacological treatment.

\section{SMOKING CESSATION}

Smoking cessation is the most effective and most important intervention available in the management of COPD. Smoking contributes to the development of COPD by increasing the annual rate of decline in forced expiratory volume in 1 second $\left(\mathrm{FEV}_{1}\right)$ from a population average of about $25 \mathrm{ml}$ per year in non-smokers to an average of $40 \mathrm{ml}$ per year in smokers. ${ }^{2}$ There is, however, considerable variation around these population average rates of decline, and smokers with above average rates of decline and/or low levels of initial lung function are those most likely to go on to develop COPD. Stopping smoking is associated with a modest (less than $50 \mathrm{ml}$ ) short term increase in $\mathrm{FEV}_{1}$ which lasts for a year or so, followed by a resumption of $\mathrm{FEV}_{1}$ decline but at the nonsmoker rate. ${ }^{3}$ No other available intervention has such a marked effect on the natural history of COPD, and smoking cessation should therefore be the first priority for all smokers presenting at any stage of disease progression.

The practice of delivering smoking cessation support should follow the principles of the "five $\mathrm{A}^{\prime} \mathrm{s}^{\prime \prime}$ listed in box $1 .{ }^{4}$ It should be recognised that not all smokers will be ready to make an attempt to quit but need to be helped towards a quit attempt in successive consultations. Also, addiction to nicotine is a chronic and relapsing condition that usually requires several attempts to achieve success. Detailed guideline summaries on smoking cessation interventions are available elsewhere $^{45}$ (copies of the UK guidelines are also available free of charge from the Thorax website (http://thorax.bmjjournals.com) and the US guidelines are available from http:// www.surgeongeneral.gov/tobacco). The cessation support offered to each individual smoker must be tailored to individual needs but with recognition that, in general, the more intensive the support accepted and provided in accordance with published evidence based guidelines, the greater the chance of success. The basic components of successful smoking cessation interventions include simple advice, written self-help materials, individual and group behavioural support, nicotine replacement therapy, and bupropion.

\section{Simple advice}

Each year about $1 \%$ of smokers succeed in quitting from their own initiative. Simple brief 
Box 1 The "five A's" of smoking cessation

- Ask about tobacco use

- Advise to quit

- Assess willingness to make an attempt

- Assist in quit attempt

- Arrange follow up

advice from a clinician encouraging a quit attempt increases this proportion up to about 3\%. Although modest in its effect, this intervention is easy to deliver and, if offered as a routine to all smokers, could generate over 350000 quitters in the UK in a year. Advice of this kind should be given as default to all smokers.

\section{Written self-help materials}

Written self-help materials also make a small contribution when given to support advice to quit. Examples are available online (http://www.cdc.gov/tobacco/quit/canquit.htm and from http://www.ash.org.uk/?cessation) and many other sources.

\section{Individual and group behavioural support}

Counselling and behavioural therapies for smoking cessation aim to motivate a smoker to stop, and develop skills and strategies to cope with nicotine withdrawal, psychological cues to smoke, and situations of temptation or pressure to smoke. ${ }^{56}$ Depending on the level of support accepted by the smoker, these interventions can increase cessation to about $7 \%$. Intensive interventions usually involve a formal assessment (including a motivational assessment) followed by a programme of 4-6 sessions, each lasting from 10 minutes to 1 hour, delivered to groups or on an individual basis. Intermediate interventions typically provide two sessions lasting 10-30 minutes with additional weekly follow up in person or by telephone for at least 4 weeks. Both intensive and intermediate interventions should deliver strong encouragement to smokers to use pharmacotherapy as appropriate. Recent reviews have found no significant difference between the efficacy of intensive interventions given either to groups or on an individual basis; however, group counselling is considerably less expensive to deliver.

\section{Nicotine replacement therapy (NRT)}

NRT enhances the cessation rates achieved by the above interventions by approximately $70 \% .^{7}$ It is available in several formulations including transdermal patches, gum, inhalator, nasal spray, and lozenges. Since there is no evidence that any of these formulations is any more or less effective, the choice of formulation is best left to individual preference. ${ }^{8}$ There is, however, evidence that combined treatment with patch and gum is more effective than single treatment alone, particularly for heavier smokers. ${ }^{9}$ NRT is probably best avoided in patients with unstable angina or acute cerebrovascular disease but can be justified even in these conditions in patients who continue to smoke.

\section{Bupropion}

Bupropion is an antidepressant that is also an effective smoking cessation treatment. Early experience with bupropion indicates that it is approximately similar to NRT in effectiveness when added to intensive behavioural support. ${ }^{10-12}$ The single comparative study available to date found evidence that bupropion was slightly more effective than NRT, but did not find that combining bupropion with NRT was any more effective than either treatment alone. ${ }^{11}$ The main adverse effect of bupropion is that it increases the risk of seizures and is therefore contraindicated in patients with a past history or high risk of seizure. There is also evidence that other antidepressants-specifically nortryptiline and clonidineare effective for smoking cessation, but these agents have not gained widespread use to date; clonidine in particular is associated with a relatively high profile of adverse effects. ${ }^{13}$

\section{Cost effectiveness}

Depending on the intensity of the intervention, smoking cessation interventions cost between about $£ 270$ and $£ 850$ per life-year saved and, as such, represent some of the most cost effective interventions available in medicine. ${ }^{14}$

\section{Application in COPD}

Smoking status should be established at all points of contact and appropriate cessation advice and support provided as appropriate to all patients who smoke. It is essential that all doctors caring for patients with COPD acquire the necessary personal skills to be able to initiate and ensure delivery of these levels of smoking cessation support to all of their patients.

\section{REDUCTION OF DISABILITY AND HANDICAP}

Once airway function is optimised and smoking cessation achieved, the focus of treatment should shift to the reduction of disability and reversal of handicap. In practice this means improving physical functioning by rehabilitation or performance enhancement and reducing the social impact of the disease by environmental modification. Recent emphasis on the role of the skeletal musculature in the development of disability provides a therapeutic opportunity by improving the strength, endurance, or efficiency of physical activity. ${ }^{15}$

\section{Rehabilitation and physical training}

Pulmonary rehabilitation now has an established role in the management of more advanced COPD. ${ }^{16-18}$ The success of rehabilitation is usually demonstrated by improvements in exercise capacity and health status. Proxy measures of disability include laboratory estimation of maximal capacity or endurance time. More practical field tests include the incremental and endurance shuttle walk test equivalents of laboratory examination and the 6 minute walk test. ${ }^{19-21}$ Measures of health status encompass elements of disability and handicap. In general, disease specific questionnaires such as the Chronic Respiratory Questionnaire or the St George's Respiratory Questionnaire have been shown to be more sensitive to rehabilitation than generic measures such as the SF-36 or EuroQol 5D. ${ }^{22}{ }^{23}$ However, the latter may be useful for health economic comparisons. The relationship between improvement in exercise performance and health status is not closely correlated or completely understood. However, improvement in health status does not occur in the absence of physical training, ${ }^{24}$ so successful rehabilitation programmes include elements of individually prescribed physical exercise training and are accompanied by formal disease education and family support. Whole body physical exercise appears to be a mandatory component without which improvement in neither functional performance nor health status is delivered.

The most frequently reported form of general exercise training is aerobic brisk walking or static cycling although, theoretically, any mode of exercise which uses the major muscle groups would be acceptable. As a general principle, the exercise should be precisely prescribed for the individual and the intensity increased as the programme progresses. ${ }^{25}$ Opinions about the prescription of intensity vary since it is evident that, unlike normal people or athletes, significant benefit can be derived from even low levels of training load. What is clear is that some exercise sessions have to be supervised. ${ }^{26}$ There should be $2-3$ sessions per week, each lasting about 20 minutes, and current evidence suggests that outpatient programmes should last for 6 weeks to achieve significant benefit. Interestingly, the apparent dose-response 
relationship between physical training and improvement in exercise capacity is not followed immediately by the gain in health status. ${ }^{27}$

All physical training is relatively task specific and, in most rehabilitation programmes, is predominantly lower limb endurance based. There are arguments for the addition of strength or upper limb training which might contribute to improvements in maximal capacity. ${ }^{28} 29$ It seems that pure strength training by repetition is possible in patients with COPD, but this does not appear to add to the benefits of more general exercise training. ${ }^{30}$ However, strength training may have a role in introducing severely deconditioned patients to physical activity and may possibly improve the ability to perform domestic tasks. ${ }^{31}$ The role of specific respiratory muscle training in the context of rehabilitation also remains uncertain. Although it may appear logical to improve their function through training, the evidence for wider benefit is limited and adds little to general exercise training. ${ }^{32}$ It is possible that some individuals may gain benefit from respiratory muscle training if the training intensities are higher, but convincing evidence is still lacking.

\section{Performance enhancement}

Although reversal of physical deconditioning by exercise training is the most obvious method of improving physical performance, there are other methods of enhancement. Ambulatory oxygen therapy, even when carrying a cylinder, can improve endurance exercise by a significantly useful distance compared with placebo. ${ }^{33}$ However, other devices such as positive pressure support may produce benefits in the laboratory by unloading the respiratory muscles but cannot yet be translated into a pragmatic device. ${ }^{34}$ Exercise performance can be improved by using wheeled walker devices that allow patients to support their upper body during ambulation. ${ }^{35}$ Devices that have a basket for carrying an oxygen cylinder and a seat are also likely to have an advantage by improving the patients' range. Other forms of self-powered mechanical forms of transport such as bicycles or tricycles could also be used in the appropriate setting. ${ }^{36}$

Elite athletes have sought for years to enhance their performance through legal and sometimes illegal means. Legal methods have included altitude training and nutritional manipulation. In COPD the initiation of deliberate hypoxic training seems unacceptably risky to test. However, it does appear that training on oxygen has no useful additional effect. ${ }^{37}$ Nutritional augmentation of training within pulmonary rehabilitation in COPD is also relatively unexplored. Simple calorific supplementation without associated training does not seem effective, but the combination may theoretically enhance the results of training. ${ }^{38}$ Other nutritional supplements such as creatine have been shown to improve strength in athletes and elderly people and could also be useful in COPD. ${ }^{39}$ The exploration of illegal substances by unscrupulous athletes has also provided a possible avenue of benefit. Some studies have examined the effects of testosterone and growth hormone on physical performance in COPD. ${ }^{40}$ To date the results suggest that anabolic agents can improve muscle bulk but not necessarily their strength or function. However, the field of pharmacological performance enhancement remains relatively unexplored. ${ }^{41}$

\section{Breathing retraining}

There are reasonable grounds for thinking that breathing retraining exercises may have symptomatic benefit in COPD. Hyperinflation is associated with altered partitioning of ventilation between the abdomen and rib cage, in addition to inducing respiratory muscle dysfunction. Premature expiratory flow limitation is naturally countered by pursed lip breathing in some people, while hyperventilation may also be a component of exacerbation or episodes of breathlessness.
For these reasons it has been popular to include relaxation exercises or breathing retraining in rehabilitation classes. These might include deep breathing, resistance loading, or even immersion in water. Although these may appear to be helpful in the short term, there is little evidence to support any sustained physiological effect in the absence of associated general physical training..$^{42}$ The practice of "diaphragmatic" breathing appears to be ineffective. ${ }^{43}$ This may be understandable since the abnormal breathing pattern has most likely arisen as a damage limiting compensation or reaction to altered respiratory muscle geometry. As a result, any short term improvements in gas exchange may be offset by increased work of breathing and the customary breathing pattern restored. However, in those patients who do have symptomatic hyperventilation there are good reasons to think that relaxation exercises might reduce the effect or improve self-efficacy.

\section{Organisation of care}

The global burden of COPD is set to increase and most developed countries, including the UK, have significant health costs associated with the illness. ${ }^{44}{ }^{45}$ It could be argued that the economic effects of COPD could be minimised by early detection and structured organisation of care. In contrast to other diseases, this has not yet happened and the organisation of care for COPD is generally reactive, delayed, and uncoordinated. Early detection of airflow obstruction is possible in primary care by spirometric screening of the susceptible population. This would allow targeting of health education and smoking cessation resources. Anecdotal evidence suggests that individual general practices can achieve this through specialist nurses, but there is no consistency in the practice. Other areas where there are inconsistencies or variations in practice include the assessment of respiratory disability and the management of exacerbations.

\section{Assessment of disability and handicap in COPD}

As the disease progresses, the relationship between the degree of airflow obstruction and resulting disability and handicap becomes indistinct. The prediction of exercise performance from $\mathrm{FEV}_{1}$ is inaccurate and disability may not be appreciated. This is particularly important for the patient in the context of workplace examination and assessment for financial benefits. Assessment of disability is traditionally conducted by a combination of spirometric tests and physician examination. This approach has been shown to be lacking when compared with objective exercise testing, yet the practice continues. ${ }^{46}$ There is also lack of standardisation of disability assessment between the legal domain and other areas where such judgements are made. There is some convincing evidence that people with disability from COPD do not receive the same level of social service support as those with equivalent but more obvious disabilities. ${ }^{47}$

\section{Specialist nursing services}

Acute exacerbation is a frequent cause of admission to hospital in people with COPD. Admissions are characterised by formulaic treatment and a recovery period of 8-10 days. An identifiable cause for the exacerbation is seldom found and active management usually ceases within a few hours of admission. In this situation, admission avoidance measures or early supported discharge schemes would offer significant economic benefit. There have now been several trials that suggest that such schemes can operate successfully in British hospitals, either by deflecting an acute admission or accelerating discharge. ${ }^{489}$ They appear to offer equivalent levels of care to the conventional admission and may be effective in reducing prolonged hospital stays in $15-40 \%$ of acute admissions, depending on the local circumstances.

The role of community specialist nursing for chronic COPD is less clear. Although it seems intuitively valuable, there is 
insufficient evidence that such nursing activity in the absence of rehabilitation results in reduced hospital stay or health care utilisation. $^{50}$ It may have a role in improving the quality of care, but more research about the delivery of community respiratory care is needed.

\section{Patient involvement}

There are a number of areas in which patients with COPD can assist with their management. Obviously enhanced knowledge of the disease and its treatment might improve the ability of the patient to maintain stability. However, the few trials of self- management in COPD have proved disappointing in comparison with asthma. Disease education alone does not improve exercise capacity, health status, or drug compliance, but can modify bronchodilator use. ${ }^{51}{ }^{52}$ Another area where individual patients can influence management is in the terminal stage of disease when difficult decisions can be pre-empted by advance directives. So far these have not proved very popular, but increasing patient knowledge is likely to promote discussion about these issues.

People with COPD have not traditionally had a high political profile or had much influence over health policy. This is beginning to change as patient support organisations develop the confidence to campaign for better services. The deficiencies in the provision of services for people with COPD are largely in the delivery of planned health care and nonpharmacological treatment. The pharmaceutical industry will ensure that new drug developments are brought to the attention of health professionals, but equally effective nonpharmacological treatments will not have the same advantages. In future we can expect people with lung disease themselves to contribute to setting the research agenda and to lobby for the implementation of effective services.

\section{Authors' affiliations}

M D L Morgan, Institute for Lung Health, Department of Respiratory Medicine and Thoracic Surgery, Glenfield Hospital, Leicester LE3 9QP, UK

J R Britton, Division of Respiratory Medicine, City Hospital, Nottingham NG5 IPB, UK

\section{REFERENCES}

1 British Thoracic Society. The burden of lung disease. London: British Thoracic Society, 2002

2 Kerstiens HA, Rijcken B, Schouten JP, et al. Decline of FEV, by age and smoking status: facts, figures, and fallacies. Thorax 1997;52:820-7.

3 Anthonisen NR, Connett JE, Kiley JP, et al. Effects of smoking intervention and the use of an inhaled anticholinergic bronchodilator on the rate of decline of $\mathrm{FEV}_{1}$. The Lung Health Study. JAMA 1994;272: 1497-505.

4 Anderson JE, Jorenby DE, Scott WJ, et al. Treating tobacco use and dependence : an evidence-based clinical practice guideline for tobacco cessation. Chest 2002;121:932-41.

5 West R, McNeill A, Raw M. Smoking cessation guidelines for health professionals: an update. Health Education Authority. Thorax 2000;55:987-99.

6 Raw M, McNeill A, West R. Smoking cessation guidelines for health professionals. A guide to effective smoking cessation interventions for the health care system. Health Education Authority. Thorax 1998;53(Suppl 5 Pt 1):S1-19.

7 Silagy C, Mant D, Fowler G, et al. Nicotine replacement therapy for smoking cessation. Cochrane Database Syst Rev 2000;3:CD000146.

8 Hajek P, West R, Foulds J, et al. Randomized comparative trial of nicotine polacrilex, a transdermal patch, nasal spray, and an inhaler. Arch Intern Med 1999;159:2033-8.

9 Bohadana A, Nilsson F, Rasmussen T, et al. Nicotine inhaler and nicotine patch as a combination therapy for smoking cessation: a randomized, double-blind, placebo-controlled trial. Arch Intern Med 2000;160:3128-34

10 Tashkin D, Kanner R, Bailey W, et al. Smoking cessation in patients with chronic obstructive pulmonary disease: a double-blind, placebo-controlled, randomised trial. Lancet 2001;357:1571-5.

11 Jorenby DE, Leischow SJ, Nides MA, et al. A controlled trial of sustained-release bupropion, a nicotine patch, or both for smoking cessation. N Engl J Med 1999;340:685-91.

12 Hurt RD, Sachs DP, Glover ED, et al. A comparison of sustained-release bupropion and placebo for smoking cessation. N Engl J Med 1997;337: 1195-202.
13 Hughes JR, Stead LF, Lancaster T. Antidepressants for smoking cessation. Cochrane Database Syst Rev 2001

14 Parrott S, Godfrey C, Raw M, et al. Guidance for commissioners on the cost effectiveness of smoking cessation interventions. Health Educational Authority. Thorax 1998;53(Suppl 5 Pt 2):S1-38.

15 Debigare $\mathbf{R}$, Cote $\mathrm{CH}$, Maltais F. Peripheral muscle wasting in chronic obstructive pulmonary disease. Clinical relevance and mechanisms. Am J Respir Crit Care Med 2001;164:1712-7.

16 Morgan MD, Singh S, Calverley PM, et al. British Thoracic Society statement on pulmonary rehabilitation. Thorax 2001;56:827-34.

17 American College of Chest Physicians/American Association of Cardiovascular and Pulmonary Rehabilitation (ACCP/AACVPR). Pulmonary rehabilitation: Joint ACCP/AACVPR evidence-based guidelines. Chest 1997;112:1363-96.

18 American Thoracic Society. Pulmonary rehabilitation-1999. Am J Respir Crit Care Med 1999;159:1666-82.

19 Singh SJ, Morgan MD, Scott S, et al. Development of a shuttle walking test of disability in patients with chronic airways obstruction. Thorax 1992;47:1019-24.

20 Revill SM, Morgan MD, Singh SJ, et al. The endurance shuttle walk: a new field test for the assessment of endurance capacity in chronic obstructive pulmonary disease. Thorax 1999:54:213-22.

21 Butland RJ, Pang J, Gross ER, et al. Two-, six-, and 12-minute walking tests in respiratory disease. BM (Clin Res Ed) 1982;284: 1607-8.

22 Engstrom CP, Persson LO, Larsson S, et al. Health-related quality of life in COPD: why both disease-specific and generic measures should be used. Eur Respir J 2001;18:69-76.

23 Singh SJ, Sodergren SC, Hyland ME, et al. A comparison of three disease-specific and two generic health-status measures to evaluate the outcome of pulmonary rehabilitation in COPD. Respir Med 2001;95:71-7

24 Toshima MT, Kaplan RM, Ries AL. Experimental evaluation of rehabilitation in chronic obstructive pulmonary disease: short-term effects on exercise endurance and health status. Health Psychol 1990;9:237-52

25 Vallet G, Ahmaidi S, Serres I, et al. Comparison of two training programmes in chronic airway limitation patients: standardized versus individualized protocols. Eur Respir J 1997;10:1 14-22.

26 Puente-Maestu L, Sanz ML, Sanz P, et al. Comparison of effects of supervised versus self-monitored training programmes in patients with chronic obstructive pulmonary disease. Eur Respir J 2000;15:517-25

27 Green RH, Singh SJ, Williams J, et al. A randomised controlled trial of four weeks versus seven weeks of pulmonary rehabilitation in chronic obstructive pulmonary disease. Thorax 2001;56:143-5.

28 Simpson K, Killian K, McCartney N, et al. Randomised controlled trial of weightlifting exercise in patients with chronic airflow limitation. Thorax 1992;47:70-5

29 Clark CJ, Cochrane L, Mackay E. Low intensity peripheral muscle conditioning improves exercise tolerance and breathlessness in COPD. Eur Respir J 1996;9:2590-6.

30 Bernard S, Whittom F, LeBlanc $P$, et al. Aerobic and strength training in patients with chronic obstructive pulmonary disease. Am J Respir Crit Care Med 1999;159:896-901.

31 Clark CJ, Cochrane LM, Mackay E, et al. Skeletal muscle strength and endurance in patients with mild COPD and the effects of weight training Eur Respir J 2000;15:92-7.

32 Larson JL, Covey MK, Wirtz SE, et al. Cycle ergometer and inspiratory muscle training in chronic obstructive pulmonary disease. Am J Respir Crit Care Med 1999:160:500-7.

33 Revill SM, Singh SJ, Morgan MD. Randomized controlled trial of ambulatory oxygen and an ambulatory ventilator on endurance exercise in COPD. Respir Med 2000;94:778-83.

34 Polkey MI, Hawkins P, Kyroussis D, et al. Inspiratory pressure support prolongs exercise induced lactataemia in severe COPD. Thorax 2000;55:547-9.

35 Honeyman P, Barr P, Stubbing DG. Effect of a walking aid on disability, oxygenation, and breathlessness in patients with chronic airflow limitation. J Cardiopulm Rehabil 1996;16:63-7

36 Woodcock AA, Johnson M, Geddes D. Cycling in patients with chronic airflow limitation. BM (Clin Res Ed) 1983;286:1184.

37 Garrod R, Paul EA, Wedzicha JA. Supplemental oxygen during pulmonary rehabilitation in patients with COPD with exercise hypoxaemia. Thorax 2000;55:539-43

38 Ferreira IM, Brooks D, Lacasse Y, et al. Nutritional support for individuals with COPD: a meta-analysis. Chest 2000;117:672-8.

39 Wiroth JB, Bermon S, Andrei S, et al. Effects of oral creatine supplementation on maximal pedalling performance in older adults. Eur J Appl Physiol 2001;84:533-9.

40 Casaburi R. Rationale for anabolic therapy to facilitate rehabilitation in chronic obstructive pulmonary disease. Bailliere's Clin Endocrinol Metab 1998; 12:407-18.

41 Steiner MC, Morgan MDL. Enhancing physical performance in COPD. Thorax 2001;56:73-7.

42 Cahalin LP, Braga M, Matsuo Y, et al. Efficacy of diaphragmatic breathing in persons with chronic obstructive pulmonary disease: a review of the literature. J Cardiopulm Rehabil 2002;22:7-21.

43 Gosselink RA, Wagenaar RC, Rijswijk H, et al. Diaphragmatic breathing reduces efficiency of breathing in patients with chronic obstructive pulmonary disease. Am J Respir Crit Care Med 1995; 151:1136-42.

44 Murray CJ, Lopez AD. Alternative projections of mortality and disability by cause 1990-2020: Global Burden of Disease Study. Lancet 1997;349: 1498-504. 
45 Calverley PMA, Bellamy D. The challenge of providing better care for patients with chronic obstructive pulmonary disease: the poor relation of airways obstruction? Thorax 2000;55:78-82

46 Oren A, Sue DY, Hansen JE, et al. The role of exercise testing in impairment evaluation. Am Rev Respir Dis 1987;135:230-5.

47 Yohannes AM, Roomi J, Connolly MJ. Elderly people at home disabled by chronic obstructive pulmonary disease. Age Ageing 1998;27:523-5.

48 Skwarska E, Cohen G, Skwarski KM, et al. Randomized controlled trial of supported discharge in patients with exacerbations of chronic obstructive pulmonary disease. Thorax 2000;55:907-12.

49 Barber CM, Bradshaw LM, Buttery $P$, et al. Assisted discharge for patients with exacerbations of COPD. Thorax 2001;56:417-8.
50 Smith B, Appleton S, Adams R, et al. Home care by outreach nursing for chronic obstructive pulmonary disease (Cochrane Review). Cochrane Database Syst Rev 2001;3:CD000994.

51 Gallefoss F, Bakke PS. How does patient education and self-management among asthmatics and patients with chronic obstructive pulmonary disease affect medication? Am J Respir Crit Care Med 1999:160:2000-5.

52 Gallefoss F, Bakke PS, Rsgaard PK. Quality of life assessment after patient education in a randomized controlled study on asthma and chronic obstructive pulmonary disease. Am J Respir Crit Care Med $1999 ; 159: 812-7$.

\section{LUNG ALERT}

\section{Telephone "asthma clinics"?}

$\Delta$ Pinnock H, Bawden R, Proctor S, et al. Accessibility, acceptability and effectiveness in primary care of routine telephone review of asthma: pragmatic, randomised controlled trial. BM 2003;326:477-9

A thma guidelines highlight the importance of regular review because non-attendees have increased morbidity. This study is the first to look at telephone consultation as a means of improving review rates. Eligible patients were adult ( $>18$ years) asthmatics ( $>1$ year) who had requested an inhaled bronchodilator within the past 6 months but had not been reviewed in 11 months or more. 932 eligible patients were identified in four practices; $278(29.8 \%)$ consented to participate and were randomised to telephone or standard face to face review, both by a trained asthma nurse. The primary outcome measures were the proportion of patients reviewed and change in asthma quality of life at 3 months. Secondary outcome measures were asthma morbidity, patient satisfaction, and consultation duration. On an "intention to review" analysis, 74\% of patients in the telephone arm were assessed compared with $48 \%$ in the standard review arm $(\mathrm{p}<0.001)$. There was no difference in the quality of life at 3 months. The study was underpowered to assess the secondary outcomes rigorously, but morbidity and satisfaction were similar and the telephone consultations shorter.

The authors conclude that telephone consultations improve access, are shorter and therefore more efficient, and do not result in clinical disadvantage or loss of satisfaction. They do not, however, report how important areas such as inhaler technique might be assessed, and the follow up period was short. This intriguing study hints at future developments in the delivery of asthma care.

J Hurst 